\title{
Applicability of Zero-offset and Offset VSP for Time-lapse monitoring - CO2CRC Otway Project Case Study
}

\author{
R.L. Pevzner* (Curtin University of Technology), M. Urosevic (Curtin \\ University of Technology) \& S. Nakanishi (Schlumberger)
}

\section{SUMMARY}

Time-lapse seismic technology is proven to be a powerful tool for monitoring of reservoir depletion or fluid (such as gas, water or steam) injection into subsurface formations. While being almost standard technique for offshore reservoirs, time lapse surveys are still relatively rare used onshore due to poor repeatability of land seismic data. Borehole time-lapse seismic surveys could be a good alternative because of very stable receiver, and, in certain cases, source conditions, acquisition and processing of zero-offset and offset VSP is reasonably fast. In this paper we analyse repeated zero-offset and offset VSP acquired in within CO2CRC Otway pilot project scientific program in year 2007 (pre-injection) and year 2010 (postinjection). We address repeatability of the data and possibility to use simple VSP techniques for monitoring purposes. 


\section{Introduction}

Time-lapse seismic technology is proven to be a powerful tool for monitoring of reservoir depletion or fluid (such as gas, water or steam) injection into subsurface formations. While being almost standard technique for offshore reservoirs, time lapse surveys are still relatively rare used onshore due to poor repeatability of land seismic data caused by seasonal changes in shallow part of the section [Al-Jabri et al, 2008]. Another problem with application of time-lapse seismic surveys is high cost of surface seismic data acquisition. Borehole time-lapse seismic surveys could be a good alternative because of very stable receiver, and, in certain cases, source conditions, acquisition and processing of zero-offset and offset VSP is fast.

CO2CRC Otway project is the first Australian demonstration project of $\mathrm{CO}_{2}$ geosequestration. It consists of a number of $\mathrm{CO}_{2}$-rich gas injections $\left(20 / 80 \%\right.$ mixture of $\mathrm{CO}_{2}$ and $\left.\mathrm{CH}_{4}\right)$ to different geological formations of Otway basin, Victoria. The Phase I conducted from year 2008 to 2009 required injection of $\sim 66,000$ tonnes of the gas to be injected to depleted gas reservoir located at depth of $\sim 2 \mathrm{~km}$ (Waare C). During the Phase II, which will occur in 2010, relatively small amount (up to $5,000-10,000$ tonnes) of the gas mixture will be injected into shallow saline aquifer at the depth of $1.4 \mathrm{~km}$. To monitor very unlikely but possible leakages of gas to other formations and attempt to detect changes in the reservoirs a comprehensive monitoring and verification program was developed. The seismic part of that program includes several repeated 3D surveys (in years 2000, 2008, 2009 and 2010) [Dodds et al, 2009], two of them (2008 and 2010) were acquired simultaneously with 3D VSP, number of repeated 2D test lines and several VSP surveys acquired in two neighbouring boreholes (Naylor-1 and CRC-1) in years 2007-2010. Naylor-1 is located updip (for Waare C formation) from CRC-1 was drilled to produce gas reservoir and, then it was depleted, converted to monitoring well. CRC-1 is the borehole drilled for CO2 injection during Phase I. Distance between holes is $\sim 300 \mathrm{~m}$.

In this paper we analyse repeated zero-offset and offset VSP acquired in CRC-1 borehole in year 2007 (pre-injection) and year 2010 (post-injection). Position of offset VSP in CRC-1 was not designed to monitor changes in depleted gas reservoir however it will be used as a baseline for Phase II. We address repeatability of the data and possibility to use simple VSP techniques for monitoring purposes.

\section{VSP data acquisition}

Acquisition parameters of both VSP surveys are presented in the Table 1. Due to logistical issues first survey was acquired with relatively weak source made from Hurricane concrete breaker, however much more powerful source became available to us in year 2009 and this was used for seismic surveys conducted in 2009-2010, including VSPs.

Table 1 VSP acquisition parameters.

\begin{tabular}{|c|c|c|}
\hline & Survey I & Survey II \\
\hline Date & December, 2007 & January, 2010 \\
\hline VSP down hole tool & 3C Schlumberger VSI tool & 3C Schlumberger VSI tool \\
\hline Source & $\begin{array}{l}\text { Weight drop, concrete breakers } \\
\text { Hurricane Force } 9 \text { and } 10 \text {, } \\
\text { operational weight } 720 \mathrm{~kg} \text { and } \\
1425 \mathrm{~kg} \text { respectively }\end{array}$ & $\begin{array}{l}\text { Vibroseis, IVI Mini-Buggy, at } \\
9000 \text { lbs, } 12.5 \text { s sweep 10-150 } \\
\mathrm{Hz}\end{array}$ \\
\hline Acquisition interval & $457-2211 \mathrm{~m}$ & $517-1900 \mathrm{~m}$ \\
\hline $\begin{array}{l}\text { Receiver spacing along } \\
\text { borehole }\end{array}$ & $\begin{array}{l}15 \mathrm{~m}(517-1575 \mathrm{~m}) \\
7.5 \mathrm{~m}(1575-2211 \mathrm{~m})\end{array}$ & $\begin{array}{l}15 \mathrm{~m}(517-1455 \mathrm{~m}) \\
7.5 \mathrm{~m}(1455-1900 \mathrm{~m})\end{array}$ \\
\hline $\begin{array}{l}\text { Zero-offset VSP shot point } \\
\text { location }\end{array}$ & Azimuth $105.5^{\circ}$, offset $89.7 \mathrm{~m}$ & Azimuth $105.5^{\circ}$, offset $89.7 \mathrm{~m}$ \\
\hline Offset VSP shot point location & Azimuth $15.5^{\circ}$, offset $1024.0 \mathrm{~m}$ & Azimuth $15.5^{\circ}$, offset $1024.0 \mathrm{~m}$ \\
\hline
\end{tabular}

The same combination of sources was used for acquisition of 3D surface seismic data, weight drop for the year 2008 and Mini-Buggy - for year 2009 and year 2010. We achieved good level of 
repeatability for 2008-2009 [REF] (year 2010 data is in processing at the moment), however repeatability analysis of seismic data acquired with different sources is one of important goals of the VSP surveys.

\section{Repeatability of VSP data}

Examples of Z-component seismograms are shown in the Figure 1 (spherical divergence correction and ensemble equalisation is applied). Only repeated positions of receivers are presented. One can see that IVI Mini-Buggy (right) could generate much wider spectrum than spectrum of weight drop data (left). Wave field content generated by both sources is very similar.

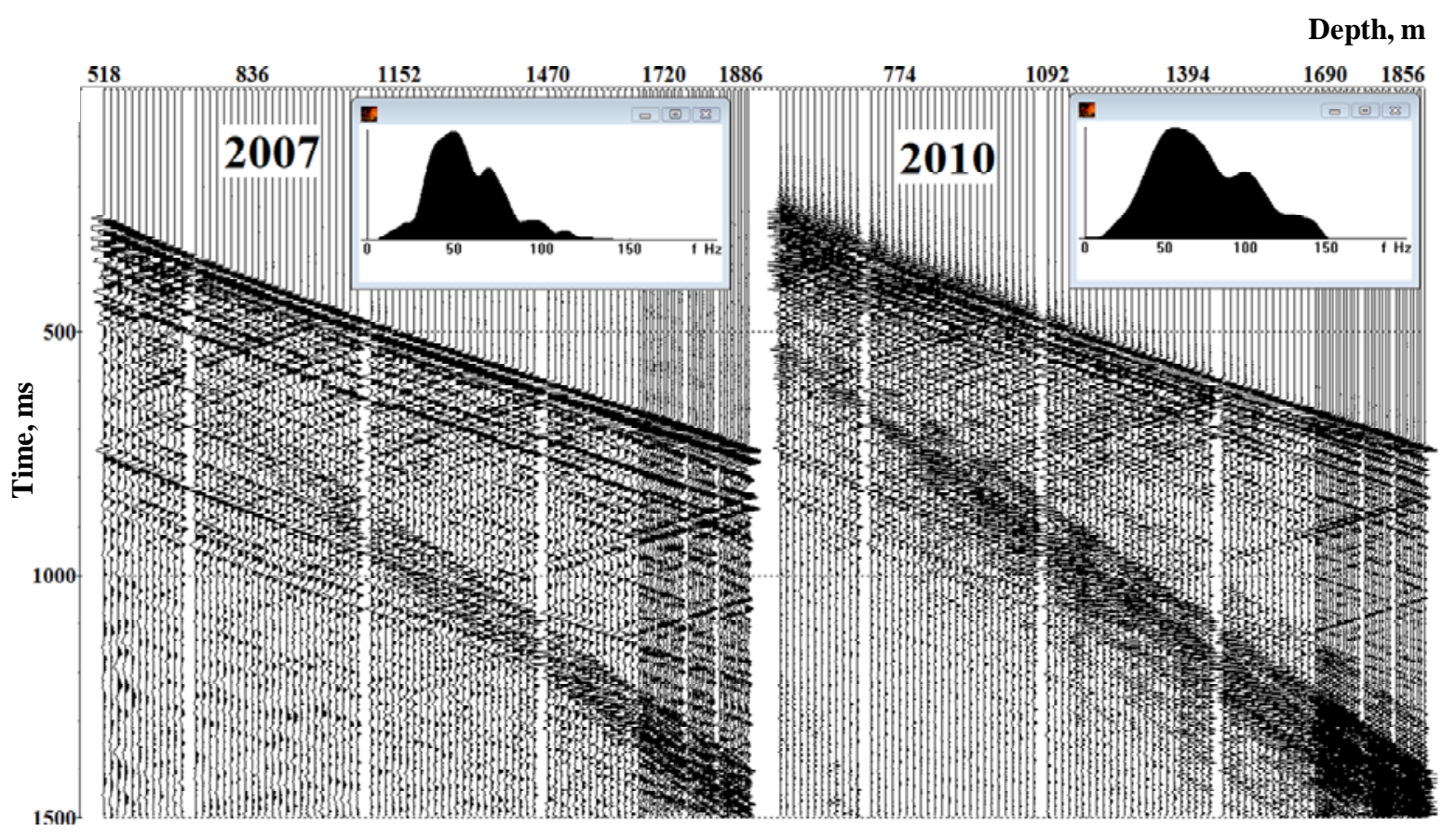

Figure 1 Zero-offset data example, Z component seismogram and amplitude spectrum of direct wave.

Transit times for both VSP surveys show reasonably good agreement. Depth drift between two surveys lays within $1 \mathrm{~ms}$ which probably could be explained by influence of attenuation to phase of the wavelet obtained after correlation of viboseis data (transit times were picked along principal extremum of the wavelet on Mini-Buggy data and along first sign change on weight drop data). However this shows that if precise transit time analyses are required, change of source type between baseline and monitor survey can introduce unwanted discrepancy.

To compare repeatability of reflected waves amplitudes one should equalize wavelet on both vibroseis and weight drop data. Luckily even standard VSP data processing utilises the fact that emitted wavelet is known due to registration of both direct and reflected waves. For purposes of time-lapse data crossequalisation we computed shaping filter for each pair of corresponded traces using downgoing wavefield to bring 2007 data to 2010 data and applied it to result of wave filed separation. This procedure is reasonably fair and will automatically take into account possible instability of source properties. Fragment of seismogram containing reflection from the Waarre C after such crossequalisation process is presented in the Figure 2. Same process was applied to offset VSP data. 


\section{Barcelona '10}

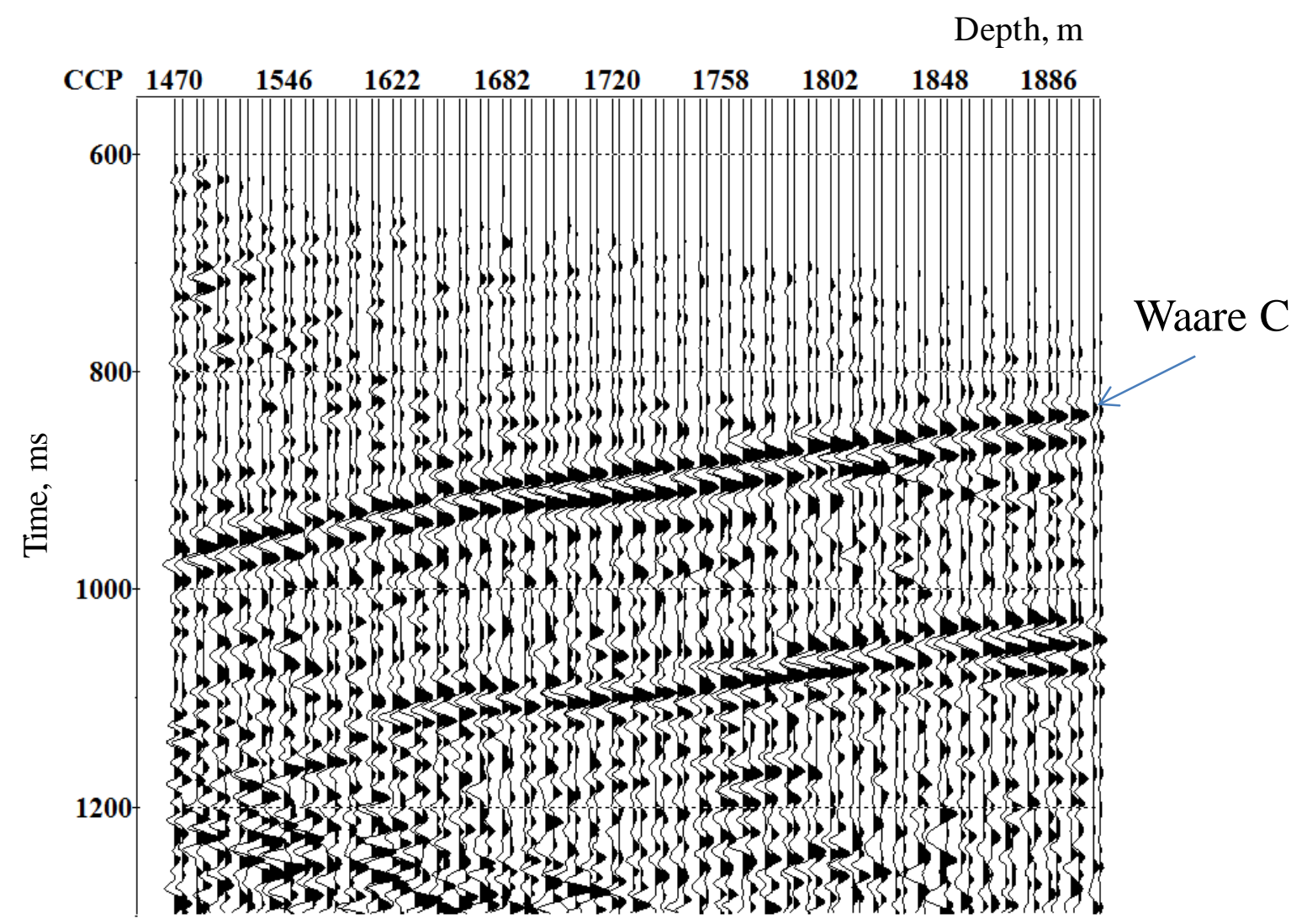

Figure 2 Result of cross-equalisation of zero-offset VSP data. In each pair of traces first represents data form year 2007 and each second - from year 2010.

It is possible to conclude that repeatability of VSP data is quite high and such standard measure of repeatability as normalised root mean square difference along strong horizons lays below $\sim 20-30 \%$ for both zero-offset and offset VSP data, which is very good value for pre-stack data.

Another important observation one can make from repeated zero-offest VSP obtained in CRC-1 borehole is that no significant changes in reflectivity is caused by $\mathrm{CO} 2$ injection could be observed at the location of injection borehole. This generally corresponds to both results of modelling and first time-lapse 3D seismic data analysis [Urosevic et al, 2009].

\section{C VSP data analysis}

Time-lapse borehole 3C measurements could provide important information about properties of both compressional and shear waves. This means that time-lapse VSP surveys could be used to observe changes in reflectivity for PP and PS waves, which could open possibility for better characterisation of changes in the reservoir. However to fully utilize this opportunity surveys with multiple shot points are required. We plan to use recently acquired 4D VSP for that purposes.

Another opportunity lays in analysis of stress-induced azimuthal anisotropy which can be done from shear wave splitting analysis. Changes in pore pressure or thickness of the reservoir could change stress filed parameters in overburden, so observation of changes in shear wave anisotropy could be used to monitor it [Olofsson et al, 2003]. Existence of strong shear wave anisotropy in Otway basin first time was reported by Turner and Hearn in 1995. Recently we have suggested an approach for multi-component velocity analysis of 3C zero-offset VSP data [Pevzner et al, 2009]. The method was 
tested on data from Naylor-1 and CRC-1 acquired earlier and showed similar anisotropy parameters for both boreholes, also they corresponds to orientation of regional stress field.

Results of multi-component velocity analysis of repeated zero-offset VSP data acquired in CRC-1 borehole for one of depth level is presented in the figure 3. One can see that azimuth of polarisation of fast $\left(\sim 140^{\circ}\right)$ and slow $\left(\sim 50^{\circ}\right)$ shear wave as well as their velocities remains unchanged.

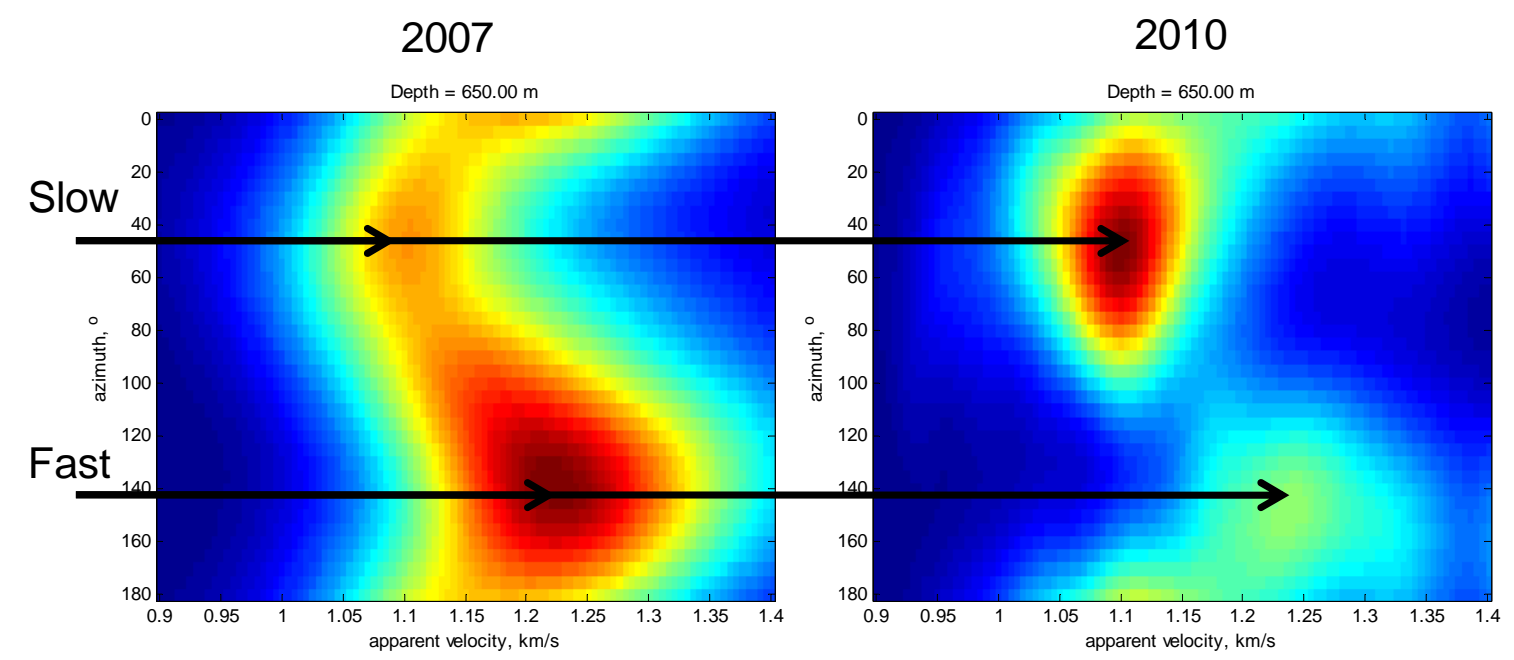

Figure 3 Results of multi-component velocity analysis of repeated zero-offset VSP data acquired in CRC-1 borehole for of depth level of $650 \mathrm{~m}$

\section{Conclusions}

Simplest VSP acquisition techniques such as zero-offset and offset VSP could be used for time-lapse monitoring of changes in reservoir. CO2CRC Otway VSP experiments proves that VSP surveys even acquired with different sources provide excellent repeatability, however if precise travel time analysis are required change of source type is not advisable. Another principal advantage of that kind of surveys is possibility to analyse both P and S waves, 3C VSP data could be used to analyse changes in anisotropy parameters induced by changes in stress field.

\section{Acknowledgements}

This work was sponsored by Australian Commonwealth Government through CO2CRC, authors are thankful to Sandeep Sharma and Charles Jenkins for making these experiments possible. Also we want to acknowledge Schlumberger field crew involved to borehole seismic data acquisition within Otway project for their great attitude and professionalism.

\section{References}

Al-Jabri, Y.Y.M., Urosevic, M and Sherlock, D. 2008, The Effect of Corrugated Limestone and the Changing of the Near Surface Conditions on CO2 Monitoring Program at Naylor-1, CO2CRC Otway Project, Victoria, Australia. First EAGE CO2 Geological Storage Workshop, Extended Abstracts, A12.

Dodds, K., Daley, T., Freifield, B., Urosevic, M., Kepic, A., and Sharma, S., 2009, Developing a monitoring and verification plan with reference to the Australian Otway CO2 pilot project, The Leading Edge, 28(7), 812-818.

Pevzner, R., Gurevich, B., Duncan, G., 2009, Estimation of Azimuthal Anisotropy from VSP Data Using Multicomponent Velocity Analysis, 71th EAGE Conference \& Exhibition incorporating SPE Europec 2009, Extended abstracts, P-182

Olofsson, B, Probert, T., Kommendal, J., Barkved, O., 2003, Azimuthal anisotropy from the Valhall 4C 3D survey, The Leading Edge, Dec. 2003, 1228-1235.

Turner, B., Hearn, S., 1995, Shear-wave splitting analysis using a single-source, dynamite VSP in the Otway Basin. Exploration Geophysiscs, 26, 519-526.

Urosevic, M, Kepic, A, Pevzner, R, Shulakova, V and Sharma, S. 2009, Injection of CO2 into a depleted gas reservoir - time lapse program and results. CO2CRC Research Symposium 2009, Sunshine Coast, 1-3 December, 2009, Abstracts, p. 58. 